\title{
Gender differences in quality of life and the course of schizophrenia: national study
}

\author{
Anat Rotstein, Efrat Shadmi, David Roe, Marc Gelkopf and Stephen Z. Levine
}

\section{Background}

Evidence from various sources suggests that females with schizophrenia tend to report lower quality of life than males with schizophrenia despite having a less severe course of the disorder. However, studies have not examined this directly.

\section{Aims \\ To examine gender differences in the association between quality of life and the risk of subsequent psychiatric hospital admissions in a national sample with schizophrenia.}

\section{Method}

The sample consisted of 989 (60.90\%) males and 635 (39.10\%) females with an ICD-10 diagnosis of schizophrenia. Quality of life was assessed and scored using the Manchester Short Assessment of Quality of Life. The course of schizophrenia was assessed from the number of psychiatric hospital admissions. Participants completed the quality of life assessment and were then followed up for 18-months for subsequent psychiatric admissions. Hazard ratios (HR) from Cox proportional hazards regression models were estimated unadjusted and adjusted for covariates (age at schizophrenia onset and birth year). Analyses were computed for males and females separately, as well as for the entire cohort.

\section{Results}

A subsample of 93 males and 55 females was admitted to a psychiatric hospital during follow-up. Higher quality of life scores were significantly $(P<0.05)$ associated with a reduced risk of subsequent admissions among males (unadjusted: $\mathrm{HR}=0.96$, 95\% Cl 0.93-0.99; adjusted HR $=0.96,95 \% \mathrm{Cl} 0.93-0.99$ ) but not among females (unadjusted: $\mathrm{HR}=0.97,95 \% \mathrm{Cl} 0.93-1.02$; adjusted $\mathrm{HR}=0.97,95 \% \mathrm{Cl}$ 0.93-1.02).

\section{Conclusions}

Quality of life in schizophrenia is a gender-specific construct and should be considered as such in clinical practice and future research.

\section{Keywords:}

Epidemiology; males; females; Manchester Short Assessment of Quality of Life; national registry data.

\section{Copyright and usage}

(c) The Author(s), 2022. Published by Cambridge University Press on behalf of the Royal College of Psychiatrists. This is an Open Access article, distributed under the terms of the Creative commons Attribution licence (https://creativecommons.org/ licenses/by/4.0/), which permits unrestricted re-use, distribution, and reproduction in any medium, provided the original work is properly cited.
Schizophrenia is a severe mental disorder with established gender differences ${ }^{1}$ in the biological, psychological, and social presentation of the disorder. ${ }^{2}$ The risk of developing schizophrenia and having a more severe course of the disorder is higher among males compared with females, ${ }^{1,3}$ with females having fewer and shorter hospital admissions. ${ }^{4-6}$ The better course for females has been attributed to later onset, allowing increased social and occupational status. ${ }^{7}$ However, occasionally, females with schizophrenia present worse outcome data than males, as is the case with quality of life Females report lower quality of life than males, ${ }^{8}$ including in global circumstances, health status and financial resources. ${ }^{9}$

The interplay between quality of life and the course of schizophrenia has been studied in the past. Higher quality of life is associated with lower levels of general psychopathology, ${ }^{10}$ less severe psychiatric symptoms $^{11}$ and lower rates of psychiatric admissions. ${ }^{12-14}$ However, no single study to date has directly considered gender differences in the association between quality of life and the course of schizophrenia. The current study aims to examine gender differences in the association between quality of life and the risk of subsequent psychiatric admissions in a national sample with schizophrenia.

\section{Method}

\section{Participants}

The current study data were derived from the Psychiatric Rehabilitation Routine Outcome Measurement Project described elsewhere. ${ }^{15}$ All procedures contributing to this study were approved by and comply with the ethical standards of the
Helsinki Committee at the Israeli Ministry of Health and the Institutional Review Board at the University of Haifa. Written informed consent was obtained from all participants. The study cohort comprised of participants with a last ICD-10 diagnosis of schizophrenia disorder $(n=1624)$, of whom 60.90\% $(n=989)$ were males and $39.10 \%(n=635)$ were females. This cohort received national psychiatric rehabilitation services in Israel. Participants with illicit drug addiction, violent behaviour or a lack of monitoring by a psychiatrist were not included in the study. Quality of life was assessed from 1 January 2013 to 19 August 2015.

\section{Additional data sources}

Demographic data (i.e. gender), information on psychiatric hospital admissions (i.e. dates) and psychiatric diagnosis (i.e. ICD-10 diagnoses) were obtained from the Israeli National Psychiatric Case Registry. This registry contains lifelong listings of psychiatric admissions in Israel from 1950 onwards, with the accompanying updated ICD-10 diagnoses given by an Israeli medical board-certified psychiatrist. The diagnoses in this registry cover over $90 \%$ of persons with schizophrenia, ${ }^{16}$ are reported to be unchanged over time ${ }^{17}$ and have acceptable sensitivity compared with research diagnostic criteria. ${ }^{18}$ The National Psychiatric Case Registry identifies all patients admitted for broadly defined schizophrenia. The registry has been used in various studies. ${ }^{19-21}$

\section{Quality of life}

Quality of life was measured using a translated version of the Manchester Short Assessment of Quality of Life, an abbreviation of 
the Lancashire Quality of Life Profile. ${ }^{22}$ Eight items measured satisfaction with physical and mental health, work or volunteering projects, social status, financial situation, family ties, leisure activities and residential status. The items were self-rated on a 5-point Likert scale. Higher scores marked higher quality of life. Research has shown that this measure has acceptable psychometric properties. ${ }^{15}$

\section{Analytic approach}

Quality of life scores were summed based on the individual item scores. The course of schizophrenia was assessed based on subsequent psychiatric hospital admissions, meaning that admissions were analysed only if they occurred after the date that the quality of life questionnaire was completed. Participants were followed up for the risk of psychiatric admissions for 18 months or until their last psychiatric admission, whichever came first (as in prior studies $^{23}$ ). To characterise the sample, descriptive statistics were computed. Next, the association between quality of life and the risk of psychiatric admissions was quantified using hazard ratios (HR) from Cox proportional hazards regression models. ${ }^{24}$ These models were computed for males and females separately, as well as for the entire cohort. All variables included in the regression models were checked for multicollinearity via the variance inflation factor for the entire cohort and the male and female subpopulations. Models were then computed unadjusted and adjusted for birth year and age at onset. Gender was an additional covariate in the model computed for the entire cohort. The proportional hazard assumption of the Cox regression models was tested by visualising Schoenfeld residual plots. ${ }^{25}$

All analyses were computed in $\mathrm{R}$ version 3.4.3 for windows using the 'survival' library ${ }^{26}$ for Cox proportional hazards regression models.

\section{Results}

\section{Sample characteristics}

The analytic sample was based on 1624 participants with schizophrenia, followed up for 18 months. Males constituted $60.90 \%$ of the total sample $(n=989)$ and females constituted $39.10 \%(n=635)$. A subsample of 148 participants was admitted to a psychiatric hospital during the follow-up time. This subsample comprised $62.84 \%$ males $(n=93)$ and $37.16 \%$ females $(n=55)$. Both samples are characterised in Table 1.

\section{Quality of life and the risk of subsequent psychiatric admissions}

The association between quality of life scores and the risk of subsequent psychiatric hospital admissions was quantified using hazard ratios from Cox proportional hazards models. All variables included in the models were checked for multicollinearity via the variance inflation factor and were found sufficiently uncorrelated $(<1.5)$. For males, higher quality of life scores were statistically significantly $(P<0.05)$ associated with a reduced likelihood of subsequent psychiatric admissions (unadjusted: $\mathrm{HR}=0.96,95 \%$ CI $0.93-0.99$; adjusted $\mathrm{HR}=0.96,95 \% \mathrm{CI} 0.93-0.99$ ). For females, there was a null association. For the entire cohort, higher quality of life scores were statistically significantly $(P<0.05)$ associated with a reduced likelihood of subsequent psychiatric hospital admissions (unadjusted: $\mathrm{HR}=0.97,95 \%$ CI $0.94-0.99$; adjusted $\mathrm{HR}=0.97$, 95\% CI 0.94-0.99), but no significant $(P=0.38)$ effect was found for gender. See Table 2 for all hazard ratios.
Table 1 Sample characteristics for the entire cohort $(n=1624)$ and the subsample admitted to psychiatric hospitals during the 18-month follow-up $(n=148)$

\begin{tabular}{|c|c|c|c|c|}
\hline \multirow[b]{2}{*}{ Variable } & \multicolumn{2}{|c|}{$\begin{array}{l}\text { Entire cohort - } \\
\text { Males: } n=989 \\
\text { females: } n=635\end{array}$} & \multicolumn{2}{|c|}{$\begin{array}{c}\text { Subsample } \\
\text { admitted during } \\
\text { follow-up - } \\
\text { Males: } n=93 ; \\
\text { females: } n=55\end{array}$} \\
\hline & Mean (s.d.) & $P$ & Mean (s.d.) & $P$ \\
\hline Quality of life score & & 0.29 & & 0.77 \\
\hline Males & $28.98(5.56)$ & & $28.38(6.41)$ & \\
\hline Females & $28.67(5.64)$ & & $28.09(5.14)$ & \\
\hline Entire cohort/subsample & $28.86(5.59)$ & & $28.27(5.95)$ & \\
\hline Age at onset, years & & $<0.001$ & & 0.82 \\
\hline Males & $26.12(9.36)$ & & $25.26(8.31)$ & \\
\hline Females & $27.96(11.11)$ & & $24.93(8.86)$ & \\
\hline Entire cohort/subsample & $26.84(10.11)$ & & $25.14(8.49)$ & \\
\hline Birth year, years & & $<0.001$ & & 0.06 \\
\hline Males & $1967(12.15)$ & & $1970(12.02)$ & \\
\hline Females & 1965 (12.31) & & 1966 (12.14) & \\
\hline $\begin{array}{l}\text { Entire cohort/ } \\
\text { subsample: }\end{array}$ & $1967(12.27)$ & & $1968(12.17)$ & \\
\hline $\begin{array}{l}\text { Number of psychiatric } \\
\text { admissions }\end{array}$ & & & & \\
\hline Males & - & & $1.67(1.22)$ & 0.88 \\
\hline Females & & & $1.64(1.14)$ & \\
\hline Entire cohort/subsample & & & $1.66(1.69)$ & \\
\hline
\end{tabular}

\section{Discussion}

Based on data from a national sample with schizophrenia, the current study is the first to explore gender differences in the association between quality of life and the course of schizophrenia. Higher quality of life was associated with a lower risk of subsequent psychiatric hospital admissions among males but not among females.

The null association found for females may be explained by several tentative mechanisms, including the severity of psychiatric symptoms, ${ }^{27}$ oestrogen effects, ${ }^{28}$ social circumstances ${ }^{29}$ and premorbid functioning. ${ }^{30}$ Gender differences may be explained by combined biological and psychosocial factors ${ }^{31}$ and should be scrutinised in future research.

In schizophrenia research, gender differences are not always examined, although they are a consistently reported aspect of the disorder. ${ }^{32}$ Our results show that investigating gender differences in schizophrenia may identify otherwise masked patterns.

Table 2 Quality of life and the risk of subsequent psychiatric hospital admissions

\begin{tabular}{lll} 
& Hazard ratio $(95 \% \mathrm{Cl})$ & $P$ \\
Males $(n=989)$ & & \\
Quality of life (unadjusted) & $0.96(0.93-0.99)$ & 0.04 \\
Birth year & $1.02(0.99-1.04)$ & 0.08 \\
Age at onset & $1.00(0.97-1.02)$ & 0.80 \\
Quality of life (adjusted) & $0.96(0.93-0.99)$ & 0.04 \\
Females ( $n=635)$ & & \\
$\quad$ Quality of life (unadjusted) & $0.97(0.93-1.02)$ & 0.38 \\
Birth year & $0.99(0.97-1.02)$ & 0.55 \\
Age at onset & $0.97(0.94-0.99)$ & 0.02 \\
Quality of life (adjusted) & $0.97(0.93-1.02)$ & 0.32 \\
Entire Cohort ( $n=1624)$ & & \\
Quality of life (unadjusted) & $0.97(0.94-0.99)$ & 0.04 \\
Gender & $0.85(0.61-1.17)$ & 0.32 \\
Birth year & $1.01(0.99-1.02)$ & 0.31 \\
Age at onset & $0.98(0.97-1.00)$ & 0.09 \\
Quality of life (adjusted) & $0.97(0.94-0.99)$ & 0.02 \\
\hline
\end{tabular}


The model we computed for the entire cohort did not reveal a significant effect for gender, unlike the analyses by gender separately. Furthermore, quality of life was significantly associated with hospital admissions for the entire sample, but within the female sample, the association was null. Exploration of gender differences may therefore have promising implications both in future research of schizophrenia and in clinical practice. ${ }^{33}$

\section{Limitations}

The current study has notable limitations. Quality of life was assessed using the Manchester Short Assessment of Quality of Life. $^{22}$ Broader measures that are tailored to schizophrenia (e.g. the Schizophrenia Quality of Life Scale ${ }^{34}$ ) exist that may yield different results. However, given the large sample of our study, the Manchester Short Assessment of Quality of Life was chosen for its quick and easy administration. Moreover, the measure has been used in multiple studies (e.g. ${ }^{35}$ ).

Our follow-up time was restricted to 18 months. This period exceeds the minimum 6-month follow-up that is considered adequate and exceeds the 12-month follow-up time in most studies. ${ }^{36}$ Nonetheless, if a longer follow-up time was used, the hospital admission rate would be greater and the results may have changed. A longer follow-up is therefore a direction for future research.

Finally, the current study did not account for all possible confounders that may influence the likelihood of psychiatric hospital admission, such as impaired global functioning, residual symptoms, adverse effects and medication non-adherence, ${ }^{37}$ or those that may specifically explain the null association found for females (e.g. oestrogen effects ${ }^{28}$ ). Age at onset was included as a confounder because it is established as associated with quality of life and psychiatric admissions in the literature. ${ }^{6,38,39}$ Future prospective studies are warranted to examine how additional factors influence the association between quality of life and psychiatric hospital admissions in both genders.

Anat Rotstein (D), PhD, Department of Community Mental Health, Faculty of Social Welfare and Health Sciences, University of Haifa, Israel; Efrat Shadmi, Cheryl Spencer Department of Nursing, Faculty of Social Welfare and Health Sciences, University of Haifa Israel; David Roe, Department of Community Mental Health, Faculty of Social Welfare and Health Sciences, University of Haifa, Israel; Marc Gelkopf, Department of Community Mental Health, Faculty of Social Welfare and Health Sciences, University of Haifa, Israel; Stephen z. Levine (D), Department of Community Mental Health, Faculty of Social Welfare and Health Sciences, University of Haifa, Israe

Correspondence: Anat Rotstein. Email: anat.rotstein@mssm.edu

First received 26 Aug 2016, final revision 10 Dec 2021, accepted 5 Jan 2022

\section{Data availability}

The data that support the findings of this study are available from the corresponding author on reasonable request.

\section{Acknowledgement}

We are grateful for the ongoing collaboration with the Mental Health Rehabilitation Department, especially Ronit Dudai and Vered Balush, and the Department of Information and Evaluation at the Ministry of Health, especially Rinat Yoffe, as well as the entire team of the Psychiatric the Ministry of Health, especially Rinat Yoffe, as well as the entire team of the Psychiatric
Rehabilitation Patient Reported Outcome Measurement project, notably Aid Rohanna, Paula Garber, Adi Telem and Ronit Mirkin. We acknowledge with thanks the support of the Center for Mental Health Research, Practice and Policy at the University of Haifa.

\section{Author contributions}

A.R.: initial and subsequent manuscript drafting, statistical analysis, data management, study conceptualisation. E.S.: critical manuscript feedback. D.R.: data management, study conceptualisation, critical manuscript feedback, mentoring. M.G.: data management, critical manuscript feedback. S.Z.L.: manuscript drafting, statistical analysis, data management, study conceptualisation, mentoring

\section{Funding}

This paper is based on the results of the Outcomes Project, which was conducted by D.R. and M.G. of the Center for Mental Health Research, Practice and Policy at the Department of community Mental Health with joint funding from the Israeli Ministry of Health and the Laszlo N. Tauber Family Foundation.

\section{Declaration of interest}

None.

\section{References}

1 Abel KM, Drake R, Goldstein JM. Sex differences in schizophrenia. Int Rev Psychiatry 2010; 22: 417-28.

2 Falkenburg J, Tracy DK. Sex and schizophrenia: a review of gender differences. Psychosis 2014; 6: 61-9.

3 Levine SZ, Rabinowitz J. A population-based examination of the role of years of education, age of onset, and sex on the course of schizophrenia. Psychiatry Res 2009; 168: 11-7.

4 Häfner H. Gender differences in schizophrenia. Psychoneuroendocrinol 2003; 28: $17-54$.

5 Levine SZ, Lurie I, Kohn R, Levav I. Trajectories of the course of schizophrenia: from progressive deterioration to amelioration over three decades. Schizophr Res 2011; 126: 184-91.

6 Rabinowitz J, Levine SZ, Häfner H. A population based elaboration of the role of age of onset on the course of schizophrenia. Schizophr Res 2006; 88: 96-101.

7 Riecher-Rössler A, Pflueger M, Borgwardt S. Schizophrenia in women. In Oxford Textbook of Women and Mental Health (ed D Kohen). Oxford University Press, 2010: 102-14.

8 Dubreucq $\mathrm{M}$, Plasse J, Gabayet F, Blanc 0 , Chereau I, Cervello S, et al. Sex differences in recovery-related outcomes and needs for psychiatric rehabilitation in people with schizophrenia spectrum disorder. J Clin Psychiatry 2021; 82(4): $20 \mathrm{~m} 13732$.

9 Huppert JD, Weiss KA, Lim R, Pratt S, Smith TE. Quality of life in schizophrenia: contributions of anxiety and depression. Schizophr Res 2001; 51: 171-80.

10 Packer S, Husted J, Cohen S, Tomlinson G. Psychopathology and quality of life in schizophrenia. J Psychiatry Neurosci 1997; 22: 231-4.

11 Desalegn D, Girma S, Abdeta T. Quality of life and its association with psychiatric symptoms and socio-demographic characteristics among people with schizophrenia: a hospital-based cross-sectional study. PLoS One 2020; 15(2): e0229514.

12 Boyer L, Baumstarck K, Boucekine M, Blanc J, Lançon C, Auquier P. Measuring quality of life in patients with schizophrenia: an overview. Expert Rev Pharmacoecon Outcomes Res 2013; 13: 343-9.

13 Lasalvia A, Bonetto C, Malchiodi F, Salvi G, Parabiaghi A, Tansella M, et al. Listening to patients' needs to improve their subjective quality of life. Psychol Med 2005; 35: 1655-65.

14 Voruganti L, Heslegrave R, Awad AG, Seeman MV. Quality of life measurement in schizophrenia: reconciling the quest for subjectivity with the question of reliability. Psychol Med 1998; 28: 165-72.

15 Roe D, Gelkopf M, Gornemann MI, Baloush-Kleinman V, Shadmi E. Implementing routine outcome measurement in psychiatric rehabilitation services in Israel. Int Rev Psychiatry 2015; 27: 345-53.

16 Weiser M, Werbeloff N, Dohrenwend BP, Levav I, Yoffe R, Davidson M. Do psychiatric registries include all persons with schizophrenia in the general population? A population-based longitudinal study. Schizophr Res 2012; 135: 187-91.

17 Rabinowitz J, Slyuzberg M, Ritsner M, Mark M, Popper M, Ginath Y. Changes in diagnosis in a 9-year national longitudinal sample. Compr Psychiatry 1994; 35 : $361-5$

18 Weiser M, Kanyas K, Malaspina D, Harvey PD, Glick I, Goetz D, et al. Sensitivity of ICD-10 diagnosis of psychotic disorders in the Israeli national hospitalization registry compared with RDC diagnoses based on SADS-L. Compr Psychiatry 2005; 46: 38-42.

19 Levine SZ, Levav I, Goldberg Y, Pugachova I, Becher Y, Yoffe R. Exposure to genocide and the risk of schizophrenia: a population-based study. Psychol Med 2016; 46: 855-63.

20 Rabinowitz J, Levine SZ, Haim R, Häfner $\mathrm{H}$. The course of schizophrenia: progressive deterioration, amelioration or both? Schizophr Res 2007; 91: 254-8.

21 Ullman VZ, Levine SZ, Reichenberg A, Rabinowitz J. Real-world premorbid functioning in schizophrenia and affective disorders during the early teenage years: a population-based study of school grades and teacher ratings. Schizophr Res 2012; 136: 13-8. 
22 Priebe S, Huxley P, Knight S, Evans S. Application and results of the Manchester Short Assessment of Quality of Life (MANSA). Int J Soc Psychiatry 1999; 45: 7-12.

23 Levine SZ, Rabinowitz J. Trajectories and antecedents of treatment response over time in early-episode psychosis. Schizophr Bull 2008; 36 : 624-32.

24 Cox DR. Regression models and life-tables. In Breakthroughs in Statistics. Vol II Methodology and Distribution (eds S Kotz, NL Johnson). Springer, 1972: 527-41.

25 Schoenfeld D. Chi-squared goodness-of-fit tests for the proportional hazards regression model. Biometrika 1980; 67: 145-53.

26 Therneau TM, Lumley T. Package 'survival': Survival Analysis. CRAN, 2017.

27 Eack SM, Newhill CE. Psychiatric symptoms and quality of life in schizophrenia: a meta-analysis. Schizophr Bull 2007; 33: 1225-37.

28 Häfner $\mathrm{H}$. Onset and early course as determinants of the further course of schizophrenia. Acta Psychiatr Scand 2000; 102: 44-8.

29 Munk-Jørgensen P, Mortensen PB, Machón RA. Hospitalization patterns in schizophrenia: a 13-year follow-up. Schizophr Res 1991; 4: 1-9.

30 Childers SE, Harding CM. Gender, premorbid social functioning, and long-term outcome in DSM-III schizophrenia. Schizophr Bull 1990; 16: 309-18.

31 Riecher-Rössler A, Häfner H. Gender aspects in schizophrenia: bridging the border between social and biological psychiatry. Acta Psychiatr Scand 2000; 102: $58-62$

32 Leung $M$, Chue $P$. Sex differences in schizophrenia, a review of the literature. Acta Psychiatr Scand 2000; 101: 3-38.
33 Moldin SO. Gender and schizophrenia. In Gender and its Effects on Psychopathology (ed E Frank). American Psychiatric Association Publishing, 2000: 169-86.

34 Wilkinson G, Hesdon B, Wild D, Cookson RON, Farina C, Sharma V, et al. Self-report quality of life measure for people with schizophrenia: the SQLS. Br J Psychiatry 2000; 177: 42-6.

35 Savill M, Orfanos S, Reininghaus U, Wykes T, Bentall R, Priebe S. The relationship between experiential deficits of negative symptoms and subjective quality of life in schizophrenia. Schizophr Res 2016; 176: 387-91.

36 Leucht S, Barnes TRE, Kissling W, Engel RR, Correll C, Kane JM. Relapse prevention in schizophrenia with new-generation antipsychotics: a systematic review and exploratory meta-analysis of randomized, controlled trials. Am J Psychiatry 2003; 160: 1209-22.

37 Higashi K, Medic G, Littlewood KJ, Diez T, Granström O, De Hert M. Medication adherence in schizophrenia: factors influencing adherence and consequences of nonadherence, a systematic literature review. Ther Adv Psychopharmacol 2013; 3: 200-18.

38 DeLisi LE. The significance of age of onset for schizophrenia. Schizophr Bull 1992; 18: 209-15.

39 Rotstein A, Roe D, Gelkopf M, Levine SZ. Age of onset and quality of life among males and females with schizophrenia: a national study. Eur Psychiatry 2018; 53: 100-6. 